\title{
PAISAGENS E GENTES DA FRONTEIRA: POVOAMENTO E URBANIZAÇÃO DA AMAZÔNIA (SÉCULOS XVII E XVIII)
}

\author{
Janaina Valéria Pinto Camilo
}

\begin{abstract}
Resumo: Este artigo tem por objetivo apresentar parte da pesquisa realizada sobre a construção da fronteira Amazônica, especificamente, a Capitania do Grão-Pará e Maranhão, entre os séculos XVII e XVIII, quando das viagens de exploração e demarcação previstas, neste último caso, pelo Tratado de Madri (1750 a 1761). O conjunto de documentos diz respeito a mapas e plantas arquitetônicas produzidos por engenheiro militares e padres matemáticos e, também, correspondências trocadas entre o Governador Francisco Xavier Mendonça Furtado com o Marquês de Pombal e com administrados das vilas da capitania, citando a necessidade de povoamento do Cabo Norte e as condições precárias de algumas fortificações e a urgência de se construir outras mais modernas, seguidas de outras construções religiosas e civis.
\end{abstract}

Palavras-Chaves: Amazônia nos séculos XVII e XVIII. Fronteira. Capitania do Grão-Pará e Maranhão.

\section{LANDSCAPES AND FRONTIER PEOPLE: POPULATION AND URBANIZATION OF THE AMAZON (17th AND 18th CENTURIES)}

\begin{abstract}
This article aims to present part of the research carried out on the construction of the Amazon frontier, specifically, the Captaincy of Grão-Pará and Maranhão, between the 17th and 18th centuries, during the exploration and demarcation trips provided, in the latter case, by the Treaty of Madrid (1750 to 1761). The set of documents refers to maps and architectural plans produced by military engineers and mathematical priests, and also correspondence between Governor Francisco Xavier Mendonça Furtado with the Marquis of Pombal and with administrators from the captaincy's villages, citing the need to populate the Cabo Norte and the precarious conditions of some fortifications and the urgency to build more modern ones, followed by other religious and civil constructions.
\end{abstract}

Keywords: Amazon in the 17th and 18th centuries. Frontier. Captaincy of Grão-Pará and Maranhão.

\section{PAISAJES Y PUEBLOS FRONTERIZOS: POBLACIÓN Y URBANIZACIÓN DE LA AMAZONÍA (SIGLOS XVII Y XVIII)}

Resumen: Este artículo tiene como objetivo presentar parte de la investigación realizada sobre la construcción de la frontera amazónica, en concreto, la Capitanía de Grão-Pará y Maranhão, entre los siglos XVII y XVIII, durante los viajes de exploración y demarcación previstos, en este último caso, por el Tratado de Madrid (1750 a 1761). El conjunto de documentos se refiere a mapas y planos arquitectónicos elaborados por ingenieros militares y sacerdotes matemáticos, y también correspondencia entre el gobernador Francisco Xavier Mendonça Furtado con el marqués de Pombal y con administradores de las aldeas de la capitanía, citando la necesidad de poblar el Cabo Norte y las precarias condiciones de algunas fortificaciones y la urgencia de construir otras más modernas, seguidas de otras construcciones religiosas y civiles.

Palabras clave: Amazonas en los siglos XVII y XVIII. Frontera. Capitanía de Grão-Pará y Maranhão.

\footnotetext{
${ }^{1}$ Doutora em História Cultural pela Universidade Estadual de Campinas, professora do Centro de Formação de Professores da Universidade Federal de Campina Grande - CFP/UFCG e Professora Convidada do Mestrado Profissional em Ensino de História da Universidade Regional do Cariri - ProfHistória - Urca.
}

Revista Escritas do Tempo - v. 3, n. 7, jan-abr/2021 - p. 8-28 


\section{Introdução}

Este artigo refere-se à parte da minha tese de doutorado, intitulada "A medida da floresta: as viagens de exploração e demarcação pelo "País das Amazonas" (séculos XVII e XVIII)", defendida na Linha de Pesquisa História Cultural, do Programa de PósGraduação em História da Universidade Estadual de Campinas - UNICAMP, em 2008. Durante a escrita da tese, me deparei com importantes documentos que revelaram mapas e plantas arquitetônicas produzidos por engenheiros militares e padres matemáticos nomeados para Comissão Demarcadora de Limites da Parte Norte, chefiada por Francisco Xavier de Mendonça Furtado, cujo objetivo era providenciar a demarcação do norte da colônia prevista no Tratado de Madri (1750 a 1761). ${ }^{2}$

Porém, quando analisamos os documentos sobre as viagens exploratórias e demarcatórias da Amazônia Seiscentista e Setecentista, a leitura revelou que não se deve conceber o domínio do território sem a interação entre os elementos da natureza e a sociedade com ela relacionada: o índio, a fauna e a flora, isto porque um território não se divide naturalmente, nem as culturas podem ser aprisionadas nos limites dos mapas, pois são determinadas no interior das relações travadas num espaço geocronológico, as quais os riscos cartográficos tentam representar.

Segundo Graham Burnett, apenas a documentação diplomática não é suficiente para definir a questão dos limites e resolver, em definitivo, o significado de fronteira. Assim, na linguagem desse cientista social, se uma fronteira é desenhada antes do desenvolvimento urbano ou das muitas características da "paisagem cultural", isso não implica que o mandatário desse espaço traçado assegure a posse e o governo do território (BURNETT, 2000, p. 263). Isto porque a fronteira é definida pela dinâmica de convivências entre as pessoas transportadas para o lugar para serem guardiões de fronteira. Portanto, uma fronteira é concebida por projetos de povoamento.

A partir dessas considerações, buscamos exemplos do que se produziu sobre a Amazônia e o amazônida, tentando extrair das várias formas de linguagem - sobretudo as escritas e desenhadas - as estruturas representativas da construção das fronteiras

\footnotetext{
${ }^{2}$ Como negociadores do Tratado de Madri, foram indicados, do lado português, Marco Antônio Coutinho, secretário de Estado; Tomaz da Silva Teles, embaixador na Espanha, e Alexandre de Gusmão que, entre 1730 e 1750, em Lisboa, foi secretário particular do rei D. João V. Como negociador espanhol, foi nomeado José de Carvajal y Lancaster, ministro de Estado, governador Supremo de Índias, presidente da Junta de Comércio e Moeda e Superintendente Geral das Postas e Estafetas de Dentro e Fora de Espanha.
} 
amazônicas, entre os séculos XVII e XVIII. Interessa-nos pensar, agora, as relações entre fronteira e urbanização, por considerarmos que as cidades construídas na Amazônia Colonial promoveram uma dinâmica de convivência entre diferentes personagens, imprescindível para o projeto português de assegurar o domínio sobre o território, que já não sendo mais das Amazonas, nem dos espanhóis, deveria passar a ser dos portugueses.

Os projetos urbanos desenvolvidos para Portugal e suas colônias, nos séculos XVII e mesmo XVIII, estavam influenciados pelos cânones estabelecidos pelo Renascimento, que propugnavam por um novo ordenamento sociocultural, assentado nas transformações do pensamento filosófico e científico, que transformaram a maneira dos homens verem o mundo. Neste ambiente de transformação, as cidades acabaram ganhando novos ordenamentos, estabelecendo, enfim, outros conceitos de convivência (ARAÚJO, 1998, p. 43 - 42).

Indo ao encontro das observações de Roberta Delson, notamos que o pensamento científico português, desde o século XVI, e as transformações introduzidas por engenheiros militares e padres matemáticos, de diferentes nacionalidades, contribuíram para a reorganização dos espaços, fazendo com que a vida urbana ganhasse ares de organismo vivo, o que acabou se estendendo ao espaço colonial (DELSON, 1997, p. 1). Assim, ressaltamos os valores e conhecimentos técnicos empreendidos na construção das cidades da região amazônica, no período compreendido entre os séculos XVII e XVIII, visto que os homens convocados para a demarcação dos limites do norte do Brasil foram os mesmos que reinventaram a vida na floresta.

Esse grupo de engenheiros militares que vieram para a região, num primeiro momento, para providenciar a demarcação dos pontos fronteiriços previstos pelos tratados de Utrecht (1713) e Madri (1750), acabaram produzindo uma nova Amazônia, concebida segundo os padrões arquitetônicos da Europa Setecentista.

Silva Telles afirma que o número de técnicos estrangeiros que vieram ao Brasil, desde o governo de D. João V, foi bastante elevado, notando-se a atuação de 238 engenheiros até 1822, dentre os quais havia 86 portugueses, 22 brasileiros, 16 alemães, 13 italianos, 12 franceses, 2 suecos, 1 suíço e 1 holandês, não havendo registro da nacionalidade dos outros 85. Essa quantidade preocupou o marquês de Pombal que, em 1770, por receio de espionagem, decretou que todos os cargos científicos no Brasil, que outrora foram entregues a alemães e italianos, fossem remanejados aos brasileiros ou portugueses.

Revista Escritas do Tempo - v. 3, n. 7, jan-abr/2021 - p. 8-28 
Tal decisão visava impedir que esses cientistas e engenheiros levassem para a Europa as cartas topográficas, astronômicas e mapas que pusessem em risco a soberania portuguesa na colônia.

\section{As cidades fortificadas}

Em obediência às instruções de Marquês de Pombal, entre outros serviços, esses engenheiros deveriam construir fortificações, também denominadas de praças de guerra, conforme a noção renascentista de "cidade ideal" ou "cidade militar", sendo, portanto, uma escala maior e moderna da cidade ou vila fortificada (TELLES, 1994, p. 88-89). Esse tipo de construção militar também dependeu do grande número de especialistas estrangeiros que, em Portugal, ocupavam cargos importantes, com destaque para Alexandre de Urbino (1588 - 1596), fortificador dirigido ao Brasil e que já tinha prestado importantes serviços à coroa portuguesa, como no cerco de Mazagão, em $1562^{3}$.

No Brasil, as praças de guerra não tinham um caráter exclusivamente defensivo e guarnecedor da fronteira. Posicionavam-se como instrumentos de efetivação da soberania e domínio do território pela coroa portuguesa, expressando a concretude colonizadora, principalmente depois da Restauração e ao longo do século XVIII, tendo um caráter político e prático, bem como urbanizador na sua essência e finalidade. Tal afirmação pode ser sustentada quando comparamos os modelos arquitetônicos das fortificações brasileiras com as europeias, principalmente no que diz respeito à geometria das muralhas (CONCEIÇÃO, 2000, p. 31-32).

Nos séculos XVII/XVIII, as fortificações portuguesas refletiam, sincronicamente, a formação da própria escola francesa de fortificação, pois Portugal contratou vários técnicos franceses e holandeses para modernizar e potencializar algumas fortificações que estavam obsoletas para a época e com um tempo de vida que vinha desde o período manuelino. Nesse processo de modernização, foram fundamentais as teorias de Sébastien Le Preste de Vauban, que desenvolveu seus celebrados sistemas entre 1680 e $1706 .{ }^{4}$

\footnotetext{
${ }^{3}$ Segundo Rafael Moreira, Mazagão foi a primeira obra portuguesa integralmente abaluartada e, como sublinhou Walter Rossa, foi a única cidade fundada ex-novo pelos portugueses na África. (CONCEIÇÃO, 2000, p. 26).

${ }^{4}$ Nascido em Saint Léger de Foucheret, em 1633, Sébastien Le Preste ingressou como cadete do Regimento de Conde, em 1651. Um ano mais tarde, trabalhou nas fortificações de Clermont, na Lorraine, atuação que lhe rendeu, em 1655, a credencial de Engenheiro e, a partir daí, seu acesso à corte do Rei Sol foi rápido e, graças à credibilidade que conquistou de seus superiores, foi enviado, entre 1660 e 1664, à Alemanha e aos Países Baixos. (GUTIÉRREZ; ESTERAS, 1991, p. 1).
} 
Figura 1: Planta da Fortaleza de São Jozé de Macapá que mostra o estado em que se achava a construção das Obras projectadas, quando no anno de 1773 se mandarão suspender.

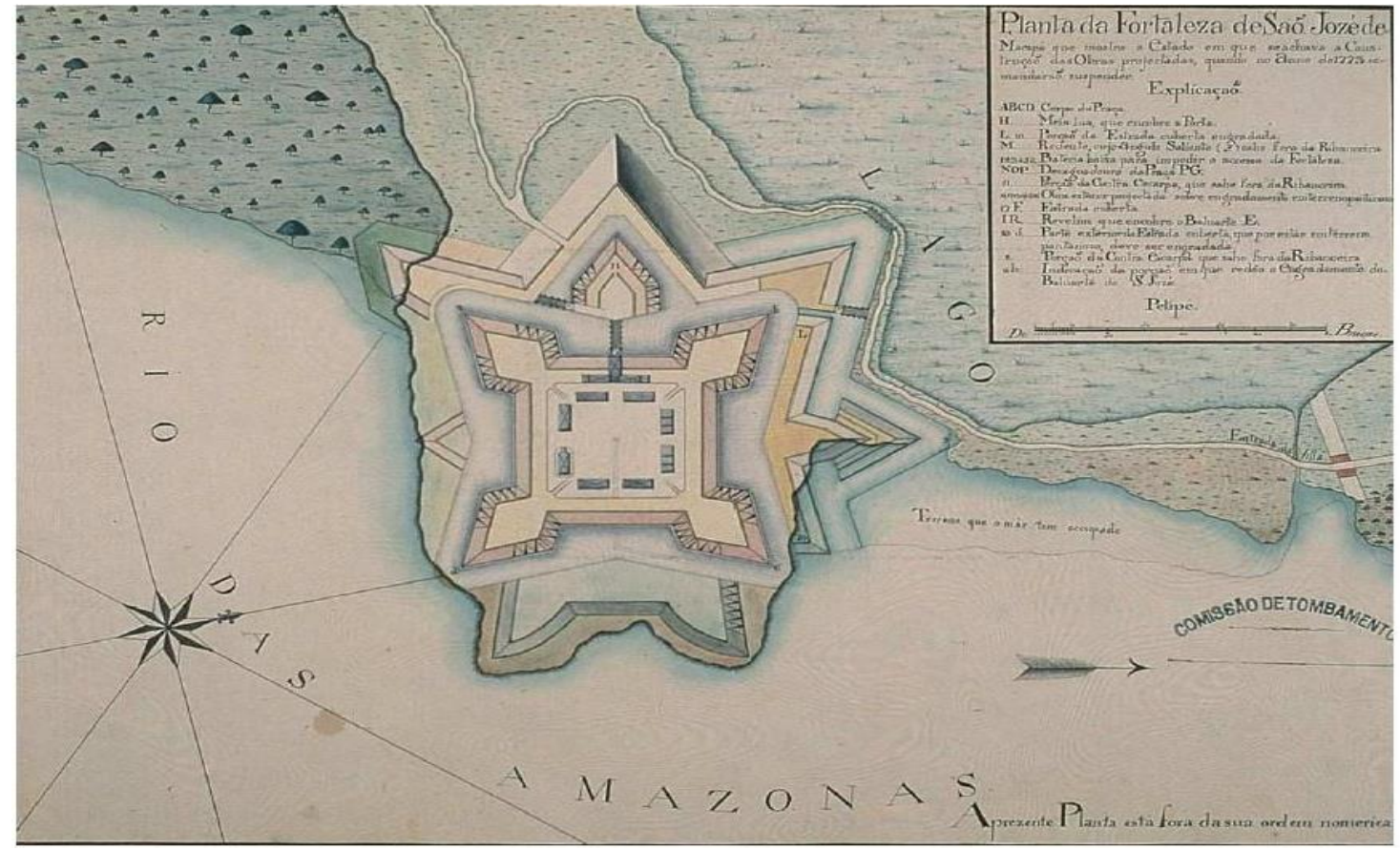

Fonte: Arquivo Histórico do Exército, Série Pará, $n^{\circ} 11.01 .22,1713$

Inserida nesse contexto de urbanização estaria a Fortaleza de São José de Macapá, que foi erigida para assegurar o domínio luso no extremo norte da colônia e, também, prevenir o lugar de um ataque inesperado. Entretanto, esta fortificação nunca foi palco de batalha, sendo sua importância atribuída ao fato de se constituir em centro dinâmico do desenvolvimento urbano da vila de São José de Macapá, a exemplo do que aconteceu com outras cidades formadas a partir de uma fortificação (vide ilustração 1). Por isso, alguns especialistas em História urbana observam que nem sempre as fortificações foram construídas face a um perigo iminente, mas acabaram por se tornar elementos integrantes do processo de urbanização do Brasil, pois compunham o conjunto de formas arquitetônicas que transformaram a paisagem no período colonial (CONCEIÇÃO, 2000, p. 31-32).

Robert David Sack, estudioso do conceito de fronteira, escreveu que a interpretação de uma fortificação está intimamente ligada aos conceitos de território e territorialidade que, por sua vez, não devem ser dissociados, pois o primeiro seria o espaço delimitado onde ocorrem os fenômenos de comportamento que explicam o segundo 
conceito que, por sua vez, apresenta as formas de controle exercidas por um grupo sobre uma determinada área ou território (SACK, 1986, p. 1).

Assim, territorialidade estaria intimamente relacionada à exploração da terra, traduzida pela política de colonização; à organização do espaço, como foram os aldeamentos ou missões e aos significados construídos sobre diferentes lugares, que podem ser traduzidos nas vilas e lugarejos que surgiram à sombra das fortificações e das aldeias. Como essas relações mudam constantemente, a melhor maneira de estudá-las é, justamente, revelando seus caracteres de mudança (SACK, 1986, p. 1).

Contudo, segundo Beatriz Bueno, se observarmos os desenhos de cidades do Brasil colonial, a partir de uma óptica social, encontraremos detalhes do que "se pretendeu construir, do que se construiu, o que se demarcou, o que se mediu, o que se conquistou ou o que se negociou nas discussões que fundamentaram os tratados de limites que beneficiaram Portugal" (BUENO, 2000, p. 57-58).

A memória patrimonial do Brasil urbano colonial, segundo Nestor Goulart Reis, “expressa em seus diversos desenhos e formas levantamentos de território, cartas geográficas, projetos de fortificações, desenhos de cidades, bem como projetos de edifícios públicos, religiosos e privados - verdadeiras obras de arte" (REIS, 2000, p. 64). Esses desenhos, na sua maioria, continuaram manuscritos, até as últimas décadas do século XVIII. Eram documentos únicos, estratégicos e de circulação restrita, pois tratavam de assuntos de Estado, sendo, portanto, submetidos exclusivamente à aprovação do Rei e seus conselheiros, com a supervisão do engenheiro-mor e do provedor de obras do reino, que os destinava aos empreiteiros e mestres de ofício, encarregados da execução das obras a serem realizadas nas Províncias do Reino e Conquistas (BUENO, 2000. p. 41).

Assim, esses desenhos foram um dos mais eficientes instrumentos de conhecimento, apropriação e controle do território, com a capacidade de fornecer à Coroa a medida do seu Império em lugares que os reis só conheciam através dos riscos dos engenheiros ou das narrativas dos viajantes. Portanto, nas folhas de papel ou de linho, constavam os planos daquilo que se pretendia conquistar, obter ou preservar, através dos princípios espaciais e estéticos que orientaram a concepção das nossas cidades planejadas e da nossa arquitetura oficial, civil e militar, onde a simetria era sinônimo de policiamento e boa ordem. 
Para atender a essas necessidades, ao longo do século XVIII, Portugal enviou para o Brasil um número significativo de engenheiros; porém, mesmo assim, o contingente não foi suficiente para dar conta de tudo o que se pretendia construir, obrigando, muitas vezes, os governadores e funcionários das capitanias, que não eram versados nessas convenções e padrões arquitetônicos, "a realizarem os desenhos que eram enviados para a metrópole acompanhados de pedidos de desculpas pela sua baixa qualidade" (BUENO, 2000, p. 55-56).

\section{São Luís, Belém e Macapá: exemplos de abstração na Amazônia}

É importante ressaltar que o início do processo de urbanização da Amazônia é assinalado pela fundação de São Luís do Maranhão e Santa Maria de Belém do GrãoPará, processo sustentado pela expulsão dos franceses, que pretendiam fundar na região uma França Equinocial.

As obras da vila de São Luís couberam à governança de Jerônimo de Albuquerque, que deveria seguir as ordens expressas no Regimento sobre a necessidade de ordenar a formação da cidade. Neste documento, afirma-se que o governador deveria "[ter] particular cuidado de acrescimento desta cidade fazendo que fique bem arruada e direita conforme a traça [...], e para seu exemplo [...] todos os moradores, fará hua casa e vivera nella" (ANAIS DA BIBLIOTECA NACIOAL apud ARAÚJO, 1998, p. 78). Para consolidar o projeto, foi contratado o engenheiro Francisco Frias de Mesquita que, em 1647, desenhou uma planta levando em consideração a topografia acidentada da ilha para a determinação do lugar onde os prédios deveriam ser construídos (vide ilustração 2).

Assim, no ponto mais alto do terreno, ficava a defesa e, no mais baixo, o conjunto de moradias e demais prédios administrativos, o que era uma característica muito comum dos projetos urbanísticos para a região, nos séculos XVII e XVIII. A fundação de Belém, por sua vez, compreende o mesmo contexto da colonização de São Luís, ficando sob responsabilidade de Francisco Caldeira Castelo Branco as ações destinadas a construir e povoar uma vila que pudesse guarnecer aquela entrada da Amazônia.

Segundo Cristovão Fernandes Duarte, a fundação de Belém, em 1616, permitiu o estabelecimento de uma rede fortificada, encarregada de defender a costa setentrional da cobiça dos franceses, que depois de serem expulsos do Maranhão podiam, conforme temiam os militares, investir contra o Norte do Brasil. A definição do lugar foi a "baía do Guajará - braço secundário da desembocadura do rio Amazonas - e surgiu como o elo 
entre o rio e o mar, tendo como calha principal o escoamento do grande rio" (DUARTE, 2000, p. 153-157). A partir de então a história de Belém significou também a conquista da Amazônia.

Renata Malcher adverte que, provavelmente, o plano urbanístico de Belém tenha sido delineado por algum funcionário que compunha o corpo administrativo sob a governança de Castelo Branco, podendo ser um engenheiro ou um piloto que, partindo da fortificação, projetou o conjunto de arruamentos para a vila. Na leitura da autora, a cidade primitiva caracteriza-se por "um teso", ou seja, uma geometria em forma de terraço, praticamente plano, sendo na parte baixa caracterizado por um alagado, chamado de Piri, não se tratando, portanto, de um terreno de grandes proporções, já que era delimitado pela baia do Guajará e pelo rio Guamá (ARAÚJO, 1998, p. 80-81).

Figura 2: Planta do forte, que disinhei, e se fica fazendo na ponta de João Dias barra na

Cidade do Maranhão... / Pedro de Azevedo Carneyro fecit. - 1692 ... q mostra pello perfil atraz as grosuras, e alturas delle como de seo fosso pela mais conveniente forma ma foy possivel, pela imcapacidade do terreno.

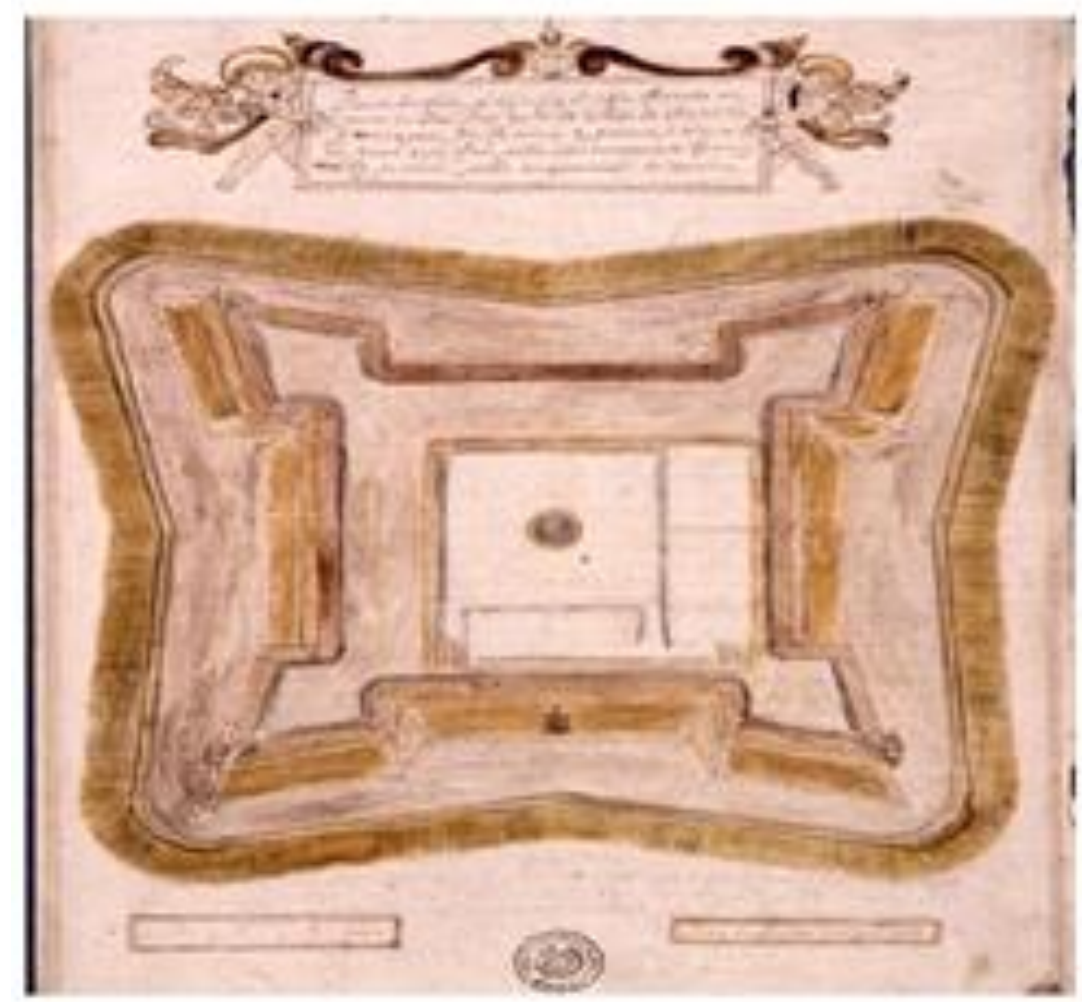

\footnotetext{
${ }^{5}$ Esta planta faz parte de um conjunto de documentos composto por mais uma planta e uma carta de Pedro de Azevedo Carneiro, datada de 15 de março de 1692, pela qual descreve todos a função de cada ponto da fortificação. (localização: AHU_CARTm_009, D. 0828/D. 0829).
} 
Entretanto, embora o terreno fosse plano e alto, diferenciando-o da topografia da região Amazônica, o lugar onde foi construído o conjunto urbanístico de Belém, por não ser área de várzea, provavelmente, era coberto por vegetação densa. Por isso, o arruamento e a eficiência da fortaleza dependeram, primeiramente, do desbaste do mato, já que nada poderia impedir a eficiência do sistema defensivo (ARAÚJO, 1998, p. 80).

O capitão-mor Bento Maciel Parente, em carta escrita a Filipe IV, em 14 de janeiro de 1623, denunciou as ruínas do forte de madeira, construído a mando de Francisco Caldeira Castelo Branco. Com isso, suas reivindicações foram aceitas e o forte primitivo acabou sendo transformado numa verdadeira fortaleza, com um baluarte com quatro peças de artilharia e fileira de casas para alojar sessenta soldados, mas com espaço suficiente par abrigar até duzentos (vide ilustração 3).

Figura 3: Planta da Cidade de Belem do Gram Pará [...]: projecto que offerece ao Ill[usstríssi]mo e Ex[celentíssi]mo S[e]n[h]or João Pereira Caldas do Concelho S.M.F. Gov[ernad]or do Grampará, Maranhão, Piauhy/ Sargento Mor Engo. Gaspar João Geraldo de Gronfeld. [ca. 1773]

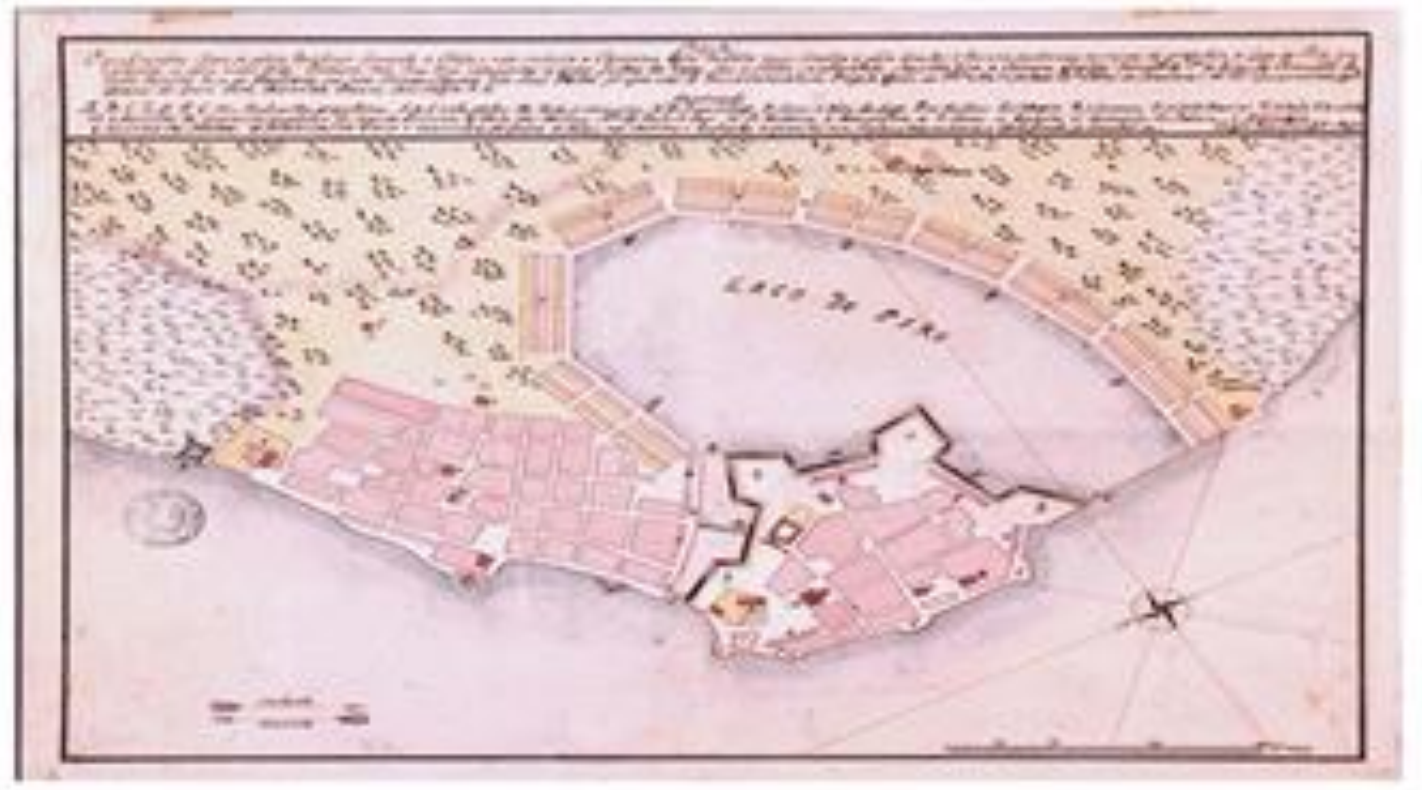

Fonte: Arquivo Histórico Ultramarino, AHU_CARTm_013, D. 0808, ca. $1773^{6}$

\footnotetext{
${ }^{6} \mathrm{Na}$ planta segue a seguinte descrição física:1 planta ms.: color., desenho a nanquim vermelho e preto. Inclui rosa-dos-ventos, aquarelada nas cores vermelha, verde, cinza e preta. 31,2 x $41 \mathrm{~cm}$. em f. $34 \mathrm{x}$ $44 \mathrm{~cm}$.Escala [ca. 1:1.7.000]. Escala gráfica de 300 braças [=9,7cm.]. Indica as marés. Vegetação representada em forma pictórica. Contém caminhos de Ss. Bovaentura, de S. José. Mostra o forte Santo Cristo e o Lago do Piri. Estão assinalados: A, B, C, D, E, F- baluartes deste novo projecto; G.H.I- m ravelims projectados, K- S ${ }^{a}$ Sé., L- Collegio M- Nossa Senhora do Carmo, P- Nossa Senhora das Mercês, R- Santo Antonio, S- Nossa Senhora do Rosário, T- Alfândega, V- Quartéis dos soldados, X- Arcenaç. YSão Jozé, ij- armazém da pólvora velho, nº1- comportas para o fosso aquático, nº2- Palácio novo. O Lago
} 
A partir dessa fortificação, que recebeu o primeiro esboço geométrico das mãos do engenheiro militar alemão João André Schwebel, em 1753, registrou-se o crescente desenvolvimento do traçado urbano, ao qual foi dado o nome de Feliz Lusitânia e, posteriormente, de Santa Maria de Belém do Grão-Pará. ${ }^{7}$

É importante ressaltar que naquela época, concomitante a esse processo de urbanização da Amazônia, ocorreu a missão de religiosos franciscanos da Província de Santo Antônio, jesuítas e carmelitas. E mesmo o padre Antônio Vieira tendo destacado que a nobreza da Companhia de Jesus sustentou-se nas "conquistas da fé, e [nas] almas convertidas de Deus" (CARDOSO; CHAMBOULEYRON, 2003, p. 47), que os lançou, desde o XVII, sobre a região, os religiosos também auxiliaram nos trabalhos de construção dos prédios e da defesa das vilas, que foram surgindo no litoral e no interior da floresta amazônica (CORTESÃO, 1956, p. 401).

Além das imagens que informam sobre a transformação da paisagem da Amazônia, é importante registrar que a obra de João Lúcio de D’Azevedo, elaborada a partir dos relatos do padre Antônio Vieira, lança luz sobre as considerações do jesuíta relacionadas ao que ele viu e viveu, em pleno século XVII, na Capitania. João Lúcio expõe, também - conforme os relatos do Padre Antônio Vieira -, que pelas ruas de Belém, "vagueavam os índios quase nus, os brancos e mestiços vestidos de algodão grosseiro da terra, de um alvacento sujo, ou então tinto da cor avermelhada do muruxy" (PE. VIEIRA apud D' AZEVEDO, 1999, p. 54).

Sobre o serviço dos índios, o jesuíta denunciou as dificultosas tarefas por eles desempenhadas, pois além de carregarem as canoas aos ombros, quando parte da jornada se fazia por terra, também eram remadores - quando a jornada retornava aos rios - e, ainda, eram construtores e reformadores de outras. E como se não fosse pouco, ainda, tinham que alimentar a tropa de religiosos e portugueses, estes últimos por suas vezes, ainda os afrontavam, chamando-os de "cães e outros nomes muito mais afrontosos" (PE VIEIRA apud CARDOSO; CHAMBOULEYRON, 2003, p. 48). Pela denúncia do

do Piri no verão chega a seccar, e nop inverno 4 palmos d'água. A execução deste projectop custarà quatro milhopens e meio.

${ }^{7}$ Schwebel chegou a Belém como integrante da Comissão Demarcadora de Limites, em 1753, e junto com ele vieram o arquiteto italiano Antônio José Landi, seu compatriota o engenheiro Antônio Gallucio e o engenheiro alemão Gaspar Gronfeld, todos integrantes da expedição técnico-científica encarregada da demarcação das fronteiras entre Portugal e Espanha previstas pelo Tratado de Madri. Como a comissão espanhola demorou a chegar, esses homens foram destinados a outros afazeres, como as construções fortificadas (DUARTE, 2000, p. 160). 
jesuíta, pode-se constatar que as intrigas entre religiosos e autoridades leigas, que ganharam força durante o governo de Mendonça Furtado, se fizeram presentes desde épocas anteriores.

As ordens religiosas nem sempre eram vistas com bons olhos, sobretudo, a Companhia de Jesus, por conta de suas relações com os indígenas que viviam nas aldeias. Por isso, esses religiosos eram tidos como "um obstáculo quase intransponível à desenfreada cobiça dos colonos" (DIAS, 1970, p. 13). Somando-se a tudo isso, havia ainda o problema das epidemias, que agravavam sobremaneira o processo colonizador.

Após várias queixas de Mendonça Furtado - governador da Capitania do GrãoPará e Maranhão e Comandante da Comissão Demarcadora de Limites e Fronteiras da Parte Norte - sobre a vulnerabilidade do Cabo Norte, o Rei determinou que fossem construídas fortificações que guarnecessem a região. Dentre muitas fortificações construídas, destaca-se a Fortaleza de São José de Macapá (vide ilustração 1), localizada à margem esquerda do Rio Amazonas.

Ainda sobre a Fortaleza de São José de Macapá observa-se que, do lado de fora das suas muralhas, surgiu a vila com o mesmo nome, a qual, na opinião de Renata Malcher, destacou-se entre as vilas que Mendonça Furtado fundou na Amazônia. De acordo com uma carta escrita pelo governador a Tomé Joaquim da Costa Real, recomenda-se que a povoação seja elevada à categoria de cidade (Carta de Francisco Xavier de Mendonça Furtado a Diogo de Mendonça Corte Real de 25 de janeiro de 1752" apud ARAÚJO, 1998, p. 149).

Durante as obras de construção da vila de Macapá, o governador Mendonça Furtado escreveu várias cartas ao Reino, dando conta do andamento do projeto urbano e dos seus moradores como fez, em 25 de janeiro de 1752, quando informou, entusiasmado, que todos os colonos estavam contentes com a fertilidade da terra e com a abundância de peixe, "que tiram do rio, ainda que com algum trabalho [pela] razão das dificuldades de ir buscar os índios as aldeias para remarem que aqui há bastante falta" (ARAÚJO, 1998, p. 149)..$^{8}$

Outras vezes, o tom do governador era de preocupação como aconteceu em fevereiro do mesmo ano, ao dar notícia sobre uma epidemia que estaria prejudicando os colonos. Entretanto, na mesma carta, procurava tranquilizar o governo de Lisboa,

\footnotetext{
${ }^{8}$ Trata-se do mesmo documento citado acima: "Carta de Francisco Xavier de Mendonça Furtado a Diogo de Mendonça Corte Real de 25 de janeiro de 1752".
}

Revista Escritas do Tempo - v. 3, n. 7, jan-abr/2021 - p. 8-28 
informando sobre a decisão tomada de levar um médico até "a povoação [que] está muito bem situada em um sítio um pouco eminente com larguíssima vista, excellentes ares e iguaes águas" (ARAÚJO, 1998, p. 149). ${ }^{9}$

Assim, a vila foi se materializando em urbe, valendo ressaltar que se fez, sobretudo, com o trabalho dos índios empregados como carpinteiros e pedreiros, que ajudaram na construção da Igreja, batizada com o nome de São José e de duas praças, batizadas São Sebastião, em homenagem a Pombal, e a outra São João, sendo provavelmente uma homenagem ao rei D. João, que foi responsável pelas negociações do Tratado de Madri, iniciando-se, assim, o processo de demarcação na Amazônia que, em seus desdobramentos, levou à fundação de Macapá. Estas praças mediam cerca de $80 \mathrm{x}$ 70 braças - conforme a planta desenhada por Gronfeld, em 1761 - e que, segundo Renata Araújo, são uma prova do dimensionamento privilegiado da vila, podendo representar, desta forma, tanto o discurso simbólico espacial "da vila do grande rio das Amazonas", quanto o ideológico, fundamentado no projeto da reforma pombalina para a região (vide anexos ilustração4). Além deste grandioso centro, havia ainda a determinação de lotes para a construção das casas, medindo cerca de "dez braças de largo por trinta de fundo" (ARAÚJO, 1998, p. 149-151, 167; 175).

A planta apresentada a seguir (ilustração 4) é de autoria do engenheiro Gaspar Gronfeld e data de 1761. Entre outros elementos, podemos observar o desenho da vila de São José de Macapá, com destaque para a Igreja, indicada pela letra A e, à sua frente, a praça de São Sebastião (letra M), localizando-se uma quadra adiante (letra N) a praça de São João onde, segundo informações prestadas por Mendonça Furtado ao bispo do Pará, foi levantado um pelourinho (apud ARAÚJO, 1998, p. 157). ${ }^{10}$

Além dessas construções, encontra-se também a projeção do forte de Macapá, desenhado antes da Fortaleza de São José pelo mesmo engenheiro alemão. Na verdade, sua construção já fora planejada muito tempo antes, visando substituir a casa forte da ilha de Santana e para consolidar, definitivamente, a política de povoamento destinada a assegurar o domínio de Portugal sobre a região. Esta fortificação era temporária, por ser de faxina e ter sido feita muito rapidamente, de abril a julho de 1761, para servir de defesa

\footnotetext{
${ }^{9} \mathrm{O}$ excerto indicado por Renata Malcher Araújo foi retirado do seguinte documento: Anais da Biblioteca e Arquivo Público do Pará. "As fortificações na Amazônia”. Tomo IV, p. 282.

${ }^{10} \mathrm{O}$ excerto indicado por Renata Malcher Araújo foi retirado do seguinte documento: POMB 162, fls. 132 a 137. Carta de Francisco Xavier de Mendonça Furtado ao bispo do Pará. Macapá, 8 de fevereiro de 1758.
}

Revista Escritas do Tempo - v. 3, n. 7, jan-abr/2021 - p. 8-28 
urgente contra desembarques no Cabo Norte. Por este motivo, o forte apresentava muitos problemas na sua estrutura arquitetônica. ${ }^{11}$

Figura 4: Planta da Villa de S. Jozé do Macapá tirada por ordem do Ill.mo e Ex.mo Sñr. Manoel Bernardo de Melo e Castro Gov.or e Capp.am General do Estado do Pará (...) em o Anno de 1761 pello Capitão Eng. Gaspar João de Gronfeld.

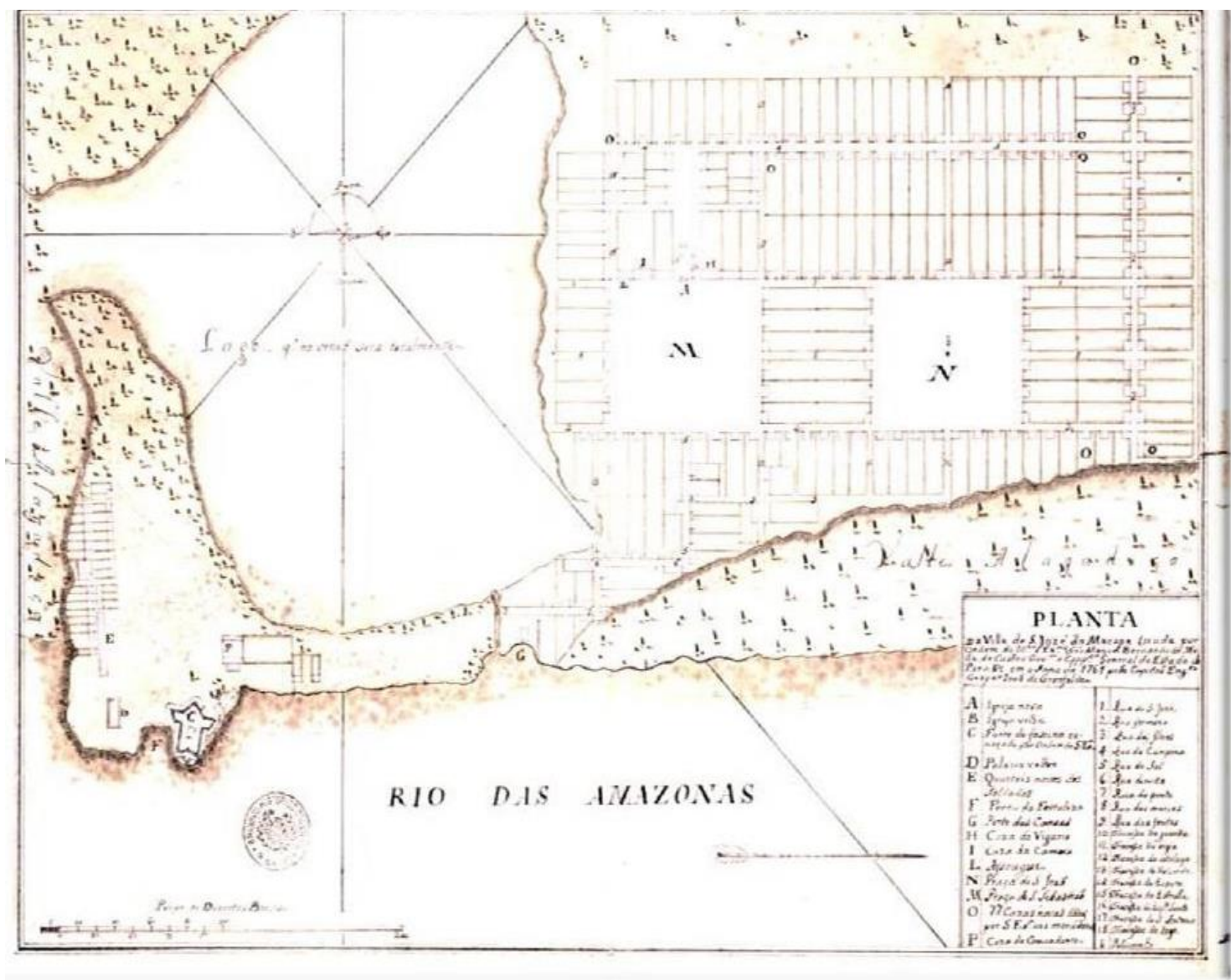

Fonte: Arquivo Histórico Ultramarino. AHU_CARTm_013, D. 0798, $1761 .^{12}$

\footnotetext{
${ }^{11}$ Adler Homero explica que existem diferenças terminológicas entre casas fortes e redutos, que são menores; baterias e fortins, que deram origem ao forte de tamanho mediano. Estes seriam as fortificações capazes de se defender de ataques por todos os lados, por períodos mais ou menos longos, sem o apoio de obras suplementares. Nesta classificação, as fortalezas seriam a maior categoria destas obras militares, incluindo em seus elementos obras externas que aumentavam seu valor defensivo. (CASTRO, 1999, p. 173).

${ }^{12}$ Na planta consta a seguinte descrição: "Descrição Física: 1 planta ms.: color., desenho a nanquim. Aguada e aquarelada nas cores vermelha e sépia.; 30 x $34 \mathrm{~cm}$. em f. 32,1 x 36, $2 \mathrm{~cm}$.Petipé de Duzentas Braças. - Escala [ca.1:3.500]. Escala gráfica de 2000 braças [=13,3 cm.]. Estão assinalados: igreja nova, igreja velha, forte de fascina começado por ordem de Sua Excelência, Palacio velho, quarteis novos dos soldados, porto da Fortaleza, Porto das Canoas, caza do Vigario, caza da camara, assougue, praça de S. João, praça de São João, Praça de São Sebastião, 77 cazas novas dadas por Sua Excelencia aos moradores, caza do comandante, Rua de São Jozé, Rua formoza, Rua das flores, rua, da Campina rua do sol, rua direita, rua da ponte, rua das Merces, rua das fontes, Travessa da guarda, travessa da Vigia, travessa da atalaya, travessa de Valverde, travessa da Espera.Inclui rosa-dos-ventos, com flor-de-lis. Vegetação representada em forma. Marca d'água: brasão encimado por uma coroa".
} 
Na verdade, até que se construísse a Fortaleza de São José de Macapá, a efetiva defesa de Macapá recaiu sobre os colonos (CASTRO, 1999, p. 170). Por isso, antes de providenciar a construção da grande fortaleza, Mendonça Furtado enviou à região várias expedições de reconhecimento e povoamento, tendo fundado em uma delas a nova povoação, depois transformada na vila de São José, em 8 de fevereiro de 1758.

Gonçalo José da Silveira Preto em carta escrita a Mendonça Furtado, em 4 dezembro de 1751, destacou a urgência de se estabelecer o povoado de Macapá, a explicação foi a seguinte:

porque temos por ali maus visinhos, e com boas terras, conforme me dizem, e na ocasião presente, sem meios, ou modo de transportar estas gentes para parte mais longe, ali os vou aquartelando, e em saindo a Frota, se Deus me der saúde, vou logo fundar a nova Povoação de São José, se S. Maj. fôr servido que assim se chame, e depois declarar-me se quer que seja vila ou cidade, ou que fique em Lugar; [...] (MENDONÇA, 1963, p. 97).

Em 1752 chegaram à vila os engenheiros Gallucio e Gronfeld, responsáveis pelas obras civis, religiosas e, também, da Fortaleza de São José de Macapá. Porém, a princípio, Mendonça Furtado preocupou-se muito em confiar a construção deste forte a engenheiros estrangeiros.

Em ofício escrito em 18 de maio de 1773, Pereira Caldas faz uma descrição da vila de São José de Macapá e, contrariando as más-querências sobre o lugar, escreveu:

O sítio he delicioso; o clima benigno; e o terreno não deixa de ser fecundo, porque produz muyto bem o Arros, o Milho, o Algodam, e em partes a Mandioca, e em quase todas a fruta. Tem dilatadas Campinas que fazem huma planície vistoza, como observei as da Villa ate aonde o Cyrugiam-mor tem o seu curral, (...) O campo tem a extenção, e pasto que pode admitir hum grande numero de gado; e de facto tem mutiplicado bastante as vacas com que S. Mage. mandou favorecer aquelle moradores. La me pareceu hum arremedo da nossa Cintra, e Collares, porque no seus potros e éguas acarretão para as suas cazas as suas colheitas em razam de ficarem distantes as suas rossas" (Arquivo Histórico Ultramarino, AHU_ACL_CU_013, cx. 70, d. 6008, de 18 de maio de 1773)

Entretanto, na mesma correspondência, advertiu que apesar da natureza e climas benéficos era necessário acudir os moradores com escravos, visto que os primeiros colonos não tinham condições financeiras, ficando a produção restrita à subsistência "não sendo a trabalhar mais que o marido, porque a mulher com a creação dos filhos se priva athe do lavor domestico" (AHU_ACL_CU_013, cx. 70, d. 6008, de 18 de maio de 1773). 
DOI: 10.47694/issn.2674-7758.v3.i7.2021.0828

\section{As gentes da fronteira}

Pelas Instruções Régias Públicas e Secretas, de 31 de maio de 1751, Mendonça Furtado foi orientado a incentivar, entre outras coisas, a miscigenação entre portugueses e índios, para assegurar um crescimento contínuo da população na região fronteiriça. Além disso, deveria trazer casais açorianos e importar escravos africanos, que serviriam como mão-de-obra para a lavoura de algodão, no Maranhão, e arroz, no Grão-Pará (MENDONÇA, 1963, $1^{\circ}$ tomo, p. 26). Convém registrar que essa mão-de-obra também foi destinada ao trabalho de construção de vilas e fortificações, garantindo, assim, o domínio luso na porção setentrional da América do Sul.

Ainda pelas Instruções Régias, percebe-se que o Rei, preocupado em assegurar a posse sobre essas terras do Cabo Norte, recomendou ao governador não somente que praticasse uma política de povoamento, mas, também, que organizasse alguma defesa para evitar desordens e, principalmente, sua conquista pelos franceses e holandeses, haja vista que o monarca já estava ciente das investidas desses países naquela região, razão pela qual, desde 1748, havia ordenado a fundação de missões nas ditas terras (MENDONÇA, 1963, tomo I, artigo 19º , p. 31).

Sobre a população da Amazônia, quando da fundação de Belém, José Veríssimo afirmou que, diante do número reduzido de mulheres da Corte no início do povoamento da região pelos europeus, a miscigenação entre brancos e índias foi uma realidade, muitas vezes conseguida pela violência sexual, pois, à época, a imigração foi quase exclusivamente masculina e militar, sendo muito raras as mulheres que acompanhavam seus maridos (VERÍSSIMO apud SARAGOÇA, 2000, p. 40).

Pedro Teixeira, em sua Relação do descobrimento do rio Amazonas, também mencionou que, nos lugares por onde passou, a caminho de Quito, nas povoações de portugueses "há poucas mulheres que sejam de sua qualidade" e alertou que "se viessem da Espanha, seriam bem recebidas" (LEITÃO, 1941, p. 105).

Além de mulheres, outros documentos reclamavam a urgência de se mandar para a região outros povoadores, como soldados, oficiais mecânicos, lavradores que podiam levar seus filhos e filhas para firmarem casamentos e, assim, "elles povoarão milhor, que estão solteiros e são mais de duzentos homens. Devem hir gados e alguns escravos da Guiné e Religiosos quais convem cousa tamanha” (IBNL, códice 249, Ms da Coleção Pombalina, fl. 239 apud SARAGOÇA, 2000, p. 41). 
E, em 1621, registrou-se a chegada dos primeiros casais açorianos ao Pará. O segundo contingente, constituído de duzentas e trinta e quatro pessoas, só chegaria a Belém cinquenta e cinco anos mais tarde, integrando um movimento que se seguiu até o governo de Mendonça Furtado.

Além desses, até o século XVIII, foram enviados para a Amazônia, em número menor, alguns degredados, anunciados em correspondências como o ofício do Arcebispo para o secretário de Estado da Marinha e Ultramar, Francisco Xavier de Mendonça Furtado, avisando sobre o envio de José Colado, natural da Vila das Galveias, em Avis, para o Estado do Pará, a fim de cumprir sentença de 10 anos de degredo em companhia de sua mulher, Francisca Luísa, por ter sido condenado pelos crimes de furto, arrombamento e fuga (Arquivo Histórico Ultramarino, AHU_ACL_013, Cx. 55, D. 5082, de 19 de abril de 1764). Não podemos deixar de registrar, porém, que a vinda dos primeiros degredados para o Grão-Pará coincidiu com o programa das sesmarias, ou seja, ocorreu em período anterior à chegada de Mendonça Furtado ao Norte da colônia.

É importante ressaltar, que estes condenados, muitas vezes, exerceram cargos importantes na capitania, servindo, sobretudo, como guardiões da fronteira, do que dá registro o ofício do governador João Pereira Caldas, para Martinho de Melo e Castro, sobre a nomeação do degredado Manuel Rebelo Seabra, para o posto de soldado de um dos regimentos da cidade de Belém do Pará (Arquivo Histórico Ultramarino, AHU_ACL_CU_013, cx. 71, D. 6058, de 28 de outubro de 1773). Outros serviram, até mesmo, nos serviços de demarcação, como foi o caso do sargento-mor engenheiro João Vasco Manuel de Braun que cumpriu pena no Pará, durante os trabalhos de demarcação do Tratado de Santo Idelfonso (Arquivo Histórico Ultramarino, AHU_ACL_CU_013, cx. 82, D. 6741, de 14 de março de 1779).

Com essas ações, a vida na fronteira institucionalizava o território, visto que seus limites eram usados para transformar e controlar o comportamento pré-existente. $\mathrm{Na}$ sociedade moderna, muitos tipos comuns de lugares foram transformados em territórios, usados tanto para conter ou restringir, quanto para excluir. Como os responsáveis pelo controle nem sempre ocupam o espaço em transformação, as intervenções espaciais - que para nós pressupõem mudanças na cultura e na paisagem - exigem um corpo administrativo. Assim, no Brasil colonial, o rei de Portugal dependia das informações de homens que trabalhavam oficialmente ou não para o Estado, para conhecer e controlar seus territórios de além-mar.

Revista Escritas do Tempo - v. 3, n. 7, jan-abr/2021 - p. 8-28 
A execução do projeto colonizador na Amazônia ficou a cargo, principalmente, da Companhia de Comércio do Grão-Pará que transportou os escravos negros dos centros de resgate da África para os serviços da Capitania. Com essa medida, assegurou a conquista agrícola das terras inexploradas do Norte. Porém a introdução dos escravos africanos exigia fartos investimentos de que não dispunham os colonos. Diante desse impasse, o governador dirigiu a responsabilidade da empreitada para a Companhia de Comércio do Grão-Pará, pois entendia que seria o único meio de arrancar o Estado do abatimento em que se encontrava. O fundo desse investimento veio dos lavradores mais abastados, convencidos de que o estabelecimento desse projeto escravista traria a fortuna esperada (ESTATUTOS DA INSTITUIÇÃO DA COMPANHIA, apud DIAS, 1970, p. 16).

Um dia antes da aprovação do alvará que criou a companhia, foi criada a lei que restituiu “aos índios do Grão-Pará e Maranhão a liberdade das suas pessoas e bens" e os nativos passaram a ser tutelados "pelos governadores, Ministros e pelos seus principaes e justiças Seculares, com inhibição das administrações dos Regulares, derrogando todas as Leys, Regimentos, Ordens e dispositivos" (Apud DIAS, 1970, p. 16). ${ }^{13}$

Com a "emancipação" do índio e a criação da Companhia de Comércio e Navegação, o poder dos jesuítas no Pará não resistiu às investidas pombalinas, sendo expulsos da metrópole e das colônias pela Lei de 3 de outubro de 1759, expedida pela Secretaria de Estado dos Negócios do Reino. Para a administração das aldeias, foi nomeado um diretor com ordens de "pelo trabalho civilisarem as Povoações" (Apud DIAS, 1970, p. 162). ${ }^{14}$

Em linhas gerais, essa política colonial de povoamento implantada no Grão-Pará, antes da chegada de Mendonça Furtado à região, e mesmo durante a sua administração, talvez tenha coincidido com a débil governança que para lá fora encaminhada, segundo as queixas do governador pombalino, influenciando a desordem generalizada que se

\footnotetext{
${ }^{13}$ O documento referente a lei citada por Manuel Nunes Dias, tem como referência completa: "Alvará com força de Ley, porque Vossa Magestade há por bem renovar a inteira e inviolável observância da Ley de doze de Setembro de mil seiscentos sincoenta e três, em quanto nella se estabeleceo que os Índios do GrãoPará e Maranhão sejam governados no temporal pelos governadores... Lisboa, 1755".

${ }^{14} \mathrm{O}$ documento referente a lei citada por Manuel Nunes Dias, tem como referência completa: “'“'Carta datada do Pará a 21 de maio de 1757 - A.B.A.P.P., doc. N 156, t. IV, pp. 184 [e, também]. Pará, 1905. Sobre a nova administração das aldeias veja-se: Directorio Que Se Deve Observar Nas Povoaçoens dos Índios do Pará e Maranhão Enquanto Sua Magestade não mandar o contrário. Lisboa, 1758”.
}

Revista Escritas do Tempo - v. 3, n. 7, jan-abr/2021 - p. 8-28 
instalara na região e que fora por ele denunciada, através das cartas escritas a seu irmão, marquês de Pombal e ao rei D. José. ${ }^{15}$

\section{Considerações Finais}

Em síntese, não parece excessivo afirmar que as fronteiras da Amazônia não se fizeram pelos tratados do século XVIII, apesar de sua importância, mas, sim, pelos improvisos frente a situações inesperadas, pelos desarranjos e desobediências que se desenrolavam por debaixo do cipoal de normas e despachos oficiais. Foram os europeus, os índios, os escravos africanos e seus descendentes - para lá conduzidos para os serviços técnicos, o trabalho intenso e o povoamento -, em suas relações de interação e conflito, que acabaram desenhando e, mais do que isso, atuando como guardiões da fronteira amazônica, definitivamente integrada ao projeto de construção do Brasil.

Contudo, as fronteiras da Amazônia não se fizeram pelos acordos diplomáticos, mas pelas relações de convivência entre as pessoas naturais da terra com aquelas que, por razões diversas - e tantas vezes involuntárias - acabaram transportadas para a região a ser demarcada. Assim, os principais protagonistas desta história não foram os reis e seus administradores diretos, que nunca participaram das comissões demarcadoras de limites, mas os engenheiros, os missionários, os índios, os negros e os civis europeus e seus descendentes mestiços, os quais, depois de transformados em sua essência, passaram a ser os verdadeiros mantenedores dos limites fronteiriços, muito mais resistentes do que os sempre desobedecidos marcos de pedra fincados nos pontos nevrálgicos.

Mesmo diante do improvável, engenheiros militares e padres matemáticos produziram mapas, desenhos, plantas e ilustrações que representaram o limite entre as terras dos civilizados e as do bárbaro; e contradizendo o comportamento dos primeiros, embalado pela cobiça do ouro, foram algozes dos segundos, já que os homens de Estado e da Guerra entre as metrópoles criaram do outro lado do Atlântico um cenário de intolerância, ambição e morte. Na Amazônia colonial, houve mais desses homens do que costumamos supor atualmente, e o resultado de suas ações teve efeitos profundos na história, não somente do norte do Brasil, mas de muitas partes do mundo, porque acabou mudando a forma de olharmos o globo terrestre.

\footnotetext{
${ }^{15}$ Referimo-nos, principalmente à carta de 21 de janeiro de 1752, escrita no Pará pelo então governador e Capitão-Geral Mendonça Furtado ao ministro Pombal. In: MENDONÇA, Carneiro. 1963, p. 196-198.
} 


\section{Referências}

Arquivo Histórico Ultramarino, AHU_ACL_013, Cx. 55, D. 5082, de 19 de abril de 1764.

Arquivo Histórico Ultramarino, AHU_ACL_CU_013, cx. 70, d. 6008, de 18 de maio de 1773.

Arquivo Histórico Ultramarino, AHU_ACL_CU_013, cx. 71, D. 6058, de 28 de outubro de 1773 .

Arquivo Histórico Ultramarino, AHU_CARTm_013, D. 0808, ca. 1773.

Arquivo Histórico Ultramarino. AHU_CARTm_013, D. 0798, 1761.

Arquivo Histórico do Exército, Série Pará, nº 11.01.22, 1713.

Arquivo Histórico Ultramarino, CARTm-009, D. 0828, 15 de março de 1692.

ARAÚJO, Renata Malcher. As cidades da Amazônia no século XVIII. Porto: Faup publicações, 1998.

BESSA, Carlos. Fronteiras do Brasil - potente realidade geopolítica e contribuição portuguesa. In Anais da Academia Portuguesa da História, Lisboa, 1989 II série, vol. 32, tomo 1, p. $9-295$.

BUENO, Beatriz Siqueira. "Desenho e desígnio - o Brasil dos engenheiros militares". In: Revista Oceanos - A construção do Brasil urbano. Portugal: Comissão Nacional para as Comemorações dos Descobrimentos Portugueses, nº .41 , janeiro/março de 2000, p. 40 58.

BURNETT, D. Graham. Masters of all they surveyed: exploration, geography; and a British El Dourado. Chicago: The University of Chicago Press, 2000.

CARDOSO, Alírio Carvalho e CHAMBOULEYRON, Rafael. Fronteiras da cristandade: Relatos jesuíticos no Maranhão e Grão-Pará (século XVII). In: DEL PRIORE, Mary e GOMES, Flávio (orgs.). Os senhores dos rios. Rio de Janeiro: Elsevier, 2003.

CASTRO, Adler Homero Fonseca de. O fecho do império: Histórias das fortificações do Cabo Norte ao Amapá de hoje. In GOMES, Flávio dos Santos; BICALHO, Maria Fernanda B. et al (org.). Nas Terras do Cabo Norte: fronteiras, colonização e escravidão na Guiana Brasileira (séculos XVIII-XIX). Belém: Editora Universitária/UFPA, 1999.

CONCEIÇÃO, Margarida Tavares da. A praça da guerra - aprendizagens entre a aula do Paço e a aula de fortificação. Revista Oceanos - A construção do Brasil urbano. Portugal: Comissão Nacional para as Comemorações dos Descobrimentos Portugueses, $\mathrm{n}^{\circ} 41$, janeiro/março de 2000, p. 24 a 38.

CORTESÃO. Jaime. História do Brasil nos velhos mapas. Rio de Janeiro: Ministério das Relações Exteriores/Instituto Rio Branco, tomo 1, 1956. 
Alexandre de Gusmão e o Tratado de Madri. Rio de Janeiro: Ministério das Relações Exteriores/Instituto Rio Branco, parte 1, tomos I e II e parte V, tomos I e II, 1956.

D’ AZEVEDO, J. Lúcio. Os jesuítas no Grão-Pará - suas missões e a colonização, Belém: Secult, série "Lendo o Pará", 1999.

DELSON, Roberta M. Novas vilas para o Brasil-Colônia. Trad. Fernando de Vasconcelos Pinto. Brasília: Ed. Alva-Ciord, 1997.

DIAS, Manuel Nunes. A Companhia Geral do Grão-Pará e Maranhão. Belém: Editora UFP, 1970.

DUARTE, Cristóvão Fernandes. São Luís e Belém: marcos inaugurais da conquista da Amazônia no período filipino. Revista Oceanos - A construção do Brasil urbano. Portugal: Comissão Nacional para as Comemorações dos Descobrimentos Portugueses, n. 41, janeiro/março de 2000, p. 152 - 160.

GARCIA, João Carlos. As cartas geográficas da Casa da Ínsua. In GARCIA, João Carlos (Org.). A mais dilatada vista do Mundo - inventário da colecção cartográfica da Casa da Ínsua, Lisboa: Comissão Nacional para Comemoração dos Descobrimentos Portugueses, 2002.

GUERREIRO, Inácio. A coleção cartográfica da Casa da Ínsua. In GARCIA, João Carlos (Org.). A mais dilatada vista do mundo - inventário da colecção cartográfica da Casa da Ínsua. Lisboa: Comissão Nacional para as Comemorações dos Descobrimentos Portugueses, 20002.

GUTIÉRREZ, Ramón; ESTERAS, Cristina. Territorio y fortificación - Vauban, Fernandez de Medrano, Ignácio Sala y Felix Prosperi: influencia en España y America, traducción de Veritable manière de bien fortifier de Mr. de Vauban por: Gerard Jalain Badoux e Daniele Steffen. España: Ediciones Tuero, 1991.

LEITÃO, C. de Melo (org. e tradução). Gaspar Carvajal, Alonso Rojas e Cristobal de Acuña, Descobrimentos do rio das Amazonas. São Paulo: Companhia Editora Nacional, 1941.

MENDONÇA, Marcos Carneiro de. A Amazônia na era pombalina. Rio de Janeiro: Instituto Histórico e Geográfico Brasileiro, 1963, tomos $1^{\circ}, 2^{\circ}$, e $3^{\circ}$.

REIS, Nestor Goulart. As principais cidades e vilas do Brasil - importância da vida urbana colonial, Revista Oceanos - A construção do Brasil urbano. Portugal: Comissão Nacional para as Comemorações dos Descobrimentos Portugueses, n. 41, janeiro/março de 2000, p. 60 - 67.

SACK, Robert David. Human territoriality. Its theory and history. Cambridge: Cambridge University Press, 1986. 
DOI: 10.47694/issn.2674-7758.v3.i7.2021.0828

SARAGOÇA, Lucinda. Da "Feliz Lusitânia" aos confins da Amazônia (1615-62). Lisboa - Santarém: Edição Cosmos, 2000.

TELLES, Pedro Carlos da Silva. História da Engenharia no Brasil (séculos XVI ao XIX). $2^{\text {a }}$ edição. Rio de Janeiro: Livros Técnicos e Científicos Editora S.A., 1984.

Artigo recebido em 26 de janeiro de 2021. Aprovado em 29 de abril de 2021.

Revista Escritas do Tempo - v. 3, n. 7, jan-abr/2021 - p. 8-28 